\title{
Luz Elena Galván Lafarga y Gerardo Antonio Galindo Peláez (coords.) (2014), Historia de la educación en Veracruz, México, Universidad Veracruzana
}

\author{
Luz Amelia Armas Briz \\ Maestra en Historia, \\ Facultad de Ciencias Políticas y Sociales \\ Universidad Autónoma de Querétaro \\ luzameliaa@yahoo.com
}

La historiografía de la educación a nivel regional nos permite vislumbrar la diversidad de políticas y realidades educativas a lo largo y ancho de nuestro país, especialmente en aquellos momentos de la historia nacional en los que se respetaba y defendía la federación, dando libertad a cada estado de dictar sus propias leyes educativas, de acuerdo a las necesidades de la región y los recursos económicos con los que se contaba. Conforme cada uno de los estados de nuestro país se ocupe de escribir su propia historia de la educación, estará abonando a una mejor comprensión de la historia de la educación en México. El caso del estado de Veracruz es importante debido a la presencia de grandes pedagogos, tanto extranjeros como locales, que lo convirtieron en un modelo a seguir por los avances que ahí se alcanzaron.

El libro que nos ocupa, coordinado por Luz Elena Galván Lafarga y Gerardo Antonio Galindo Peláez, reúne los trabajos de más de veinte investigadores profesionales de la educación. Las investigaciones se realizaron desde la perspectiva de la historia social y nos ofrecen un amplio panorama de lo que ha sido el quehacer educativo en la entidad en múltiples aspectos.

A lo largo de la lectura se pueden distinguir tres niveles de análisis. El primero tiene que ver con el efecto producido por las leyes, planes y programas educativos tanto federales como estatales en el desarrollo de la educación primaria, secundaria y profesional, desde principios del siglo XIX hasta nuestros días. Así, identificamos desde el impacto que tuvieron las reformas borbónicas en la educación de algunos pueblos indígenas, hasta la lucha por la imposición de políticas educativas, ya fueran conservadoras o liberales y la pobreza del erario 
público como freno a los avances esperados. Se analiza también el lugar que ocupó el ramo educativo en la agenda nacional en diferentes momentos de nuestra historia, la influencia de los Congresos Nacionales y las aportaciones de los Congresos Estatales, así como los discursos de los jefes políticos, figuras claves para lograr o frenar el funcionamiento educativo.

Muy interesante, el artículo de Laura Giraudo, que señala los enfrentamientos con la recién creada Secretaría de Educación Pública para defender un sistema de educación estatal ya consolidado desde finales del siglo XIX.

El segundo nivel de análisis es el más rico en contenido y tiene que ver con la construcción de la cultura escolar en Veracruz, trabajada por los investigadores desde lo que propone el historiador francés Dominique Julia. A este respecto, el artículo escrito por María Isabel Vega Muytoy plantea que desde la segunda década del siglo xIx la Cartilla Lancasteriana marcó ya la construcción de una cultura escolar, al atender aspectos concernientes al edificio escolar, los maestros, los alumnos, los libros de texto, el método y la disciplina a seguir. Siguiendo esta línea, encontramos el texto del arquitecto Jaime F. Terrazas sobre los primeros edificios construidos expresamente para servir como escuelas, siguiendo los lineamientos dictados por los Congresos, en relación a la distribución de los espacios, la ventilación e iluminación de las aulas. Otros artículos analizan la apropiación de los modelos educativos extranjeros, desde el sistema lancasteriano, el objetivo y la propuesta de la escuela activa de Freinet, instalada en la primaria experimental de San Andrés Tuxtla y en la Práctica, anexa a la Normal de Veracruz.

Belinda Arteaga y Siddharta Camargo incursionan en la formación de profesores en las escuelas normales y la fundación de la Normal Veracruzana. Ésta fue un espacio de discusión académica muy importante y ahí se formaron maestros durante varias décadas, la mayoría practicaron el magisterio fuera de Veracruz y con el transcurso de los años se convirtieron en una elite intelectual.

Los lugares para la enseñanza comercial y la enseñanza técnica también son descritos. En el caso de la enseñanza técnica, Federico Lazarín nos plantea la contradicción de que habiendo la SEP establecido una escuela industrial en Orizaba, en donde la industria textil predominaba, no se abrieran carreras y cursos libres adecuados a su vocación. La misma paradoja es planteada por Hubonor Ayala para el caso del Hospicio Municipal de Orizaba, donde la enseñanza técnica fue omitida.

La perspectiva de género también está presente. Soledad García Morales nos advierte que la educación de la mujer se fue perfilando durante el porfiriato, con la fundación de la Escuela de Enseñanza Superior para Niñas en Xalapa. Oresta López analiza la influencia que tuvo la presencia de Gabriela Mistral en el ámbito educativo nacional y local. Abel Juárez da

${ }^{1}$ Dominique Julia (1995), "La cultura escolar como objeto histórico", en Margarita Menegus y Enrique González (eds.), Historia de las universidades modernas en Hispanoamérica. Métodos y Fuentes, México, UNAM. 
cuenta de la contradicción entre el radicalismo del discurso estridentista en relación a la atención a la mujer y las prácticas conservadoras y tradicionales.

En este segundo nivel se abren nuevas líneas de estudio para el avance de la historia de la educación, tales como los dictámenes de los libros de texto y las casas editoriales que los publicaban, antes de que existiera la Secretaría de Educación Pública, cuando eran los maestros de aula los que elaboraban los textos. Un buen ejemplo de estos maestros es el que nos ofrece Luz Elena Galván en el capítulo en que analiza la trayectoria y las aportaciones de Gildardo F. Avilés, un maestro veracruzano formado por Enrique Rébsamen, desde la perspectiva de la biografía social de un hombre común, siguiendo a Francois Dosse. ${ }^{2}$ El cuerpo de fotografías antiguas y modernas de edificios, maestros, aulas y libros de texto incluidas al final del libro es una aportación importante a la comprensión de la cultura escolar.

El tercer nivel de análisis gira en torno a un acercamiento a la cuestión educativa en el presente, ofreciendo un panorama educativo que abarca todas las regiones del estado de Veracruz en las últimas décadas y las problemáticas que se deben atender. Se realiza también un análisis del desempeño de los gobernantes y una evaluación del sistema educativo actual a través de estadísticas sobre índices de analfabetismo, niveles de educación por edades, promedios de docentes y alumnos, gastos en educación y otros rubros. Se le da mayor relevancia a la educación universitaria, incluyendo un artículo con comentarios sobre el informe publicado por la Organización de la Cooperación y Desarrollo Económico (OCDE) en 2010, relativo al desempeño de instituciones de educación superior y en específico sobre las recomendaciones que ese organismo hace al estado de Veracruz.

Sin duda alguna, esta obra es un proyecto ambicioso que hace aportaciones importantes para el conocimiento del desarrollo de la educación en Veracruz y de todo el país. En entrevista realizada a Luz Elena Galván, nos comentó que la coordinación tuvo varios retos: lograr una historia de la educación regional con un enfoque distinto, siguiendo el esquema que propone Dominique Julia y encontrar a los especialistas idóneos que aportaran artículos desde esa perspectiva teórica. Otro reto fue que, al ser un proyecto auspiciado por la Secretaría de Educación de Veracruz y la Universidad Veracruzana, se tuvo que negociar la inclusión de algunos de los artículos que versan sobre la problemática del presente, por no apegarse estrictamente a lo que ellos habían planteado como un libro de historia.

Sólo me resta decir que tanto la elección de contenidos como la estructura del libro fueron muy acertados y que una vez que el lector culmine su lectura, podrá no sólo comprender los avatares de la educación de Veracruz y sus grandes logros en el transcurso de la historia, sino hacer también una seria reflexiones sobre el atraso educativo en las últimas décadas, para dar respuesta a la pregunta que ahí mismo se nos plantea: ¿dónde nos perdimos?

\footnotetext{
${ }^{2}$ François Dosse (2007), El arte de la biografía, México, Universidad Iberoamericana.
} 